\title{
Discovery of Stable Non-opioid Dynorphin A Analogues Interacting at the Bradykinin Receptors for the Treatment of Neuropathic Pain
}

\author{
Sara M. Hall,${ }^{\dagger}$ Lindsay LeBaron,${ }^{\dagger}$ Cyf Ramos-Colon, ${ }^{\dagger}$ Chaoling Qu, ${ }^{\dagger}$ Jennifer Yanhua Xie, ${ }^{\ddagger}$ \\ Frank Porreca, ${ }^{\ddagger}$ Josephine Lai, $^{\dagger}$ Yeon Sun Lee, ${ }^{\dagger, *}$ Victor J. Hruby ${ }^{\dagger}$ \\ ${ }^{\dagger}$ Department of Chemistry and Biochemistry, University of Arizona, Tucson, AZ 85721, United \\ States \\ ${ }^{+}$Department of Pharmacology, University of Arizona, Tucson, AZ 85719, United States
}


Supplemental Material

Table 1. Analytical Data for Dyn A Analogues

\begin{tabular}{|c|c|c|c|c|c|c|c|}
\hline \multirow{2}{*}{ No } & \multirow{2}{*}{$\begin{array}{l}\text { molecular } \\
\text { formula }\end{array}$} & \multicolumn{3}{|c|}{ LowMS $^{a} \quad$ HR-MS $^{b}$} & \multicolumn{2}{|r|}{ HPLC $^{c}$} & \multirow{2}{*}{$=\mathrm{aLogPs}^{d}$} \\
\hline & & observed & Observed & calcd. & $\begin{array}{l}\text { error } \\
(\mathrm{ppm})\end{array}$ & $\left(\mathrm{t}_{R}, \min \right)$ & \\
\hline 2 & $\mathrm{C}_{44} \mathrm{H}_{76} \mathrm{~N}_{14} \mathrm{O}_{8}$ & 929.5 & 929.6030 & 929.6043 & 1.4 & 10.5 & -1.60 \\
\hline 3 & $\mathrm{C}_{44} \mathrm{H}_{76} \mathrm{~N}_{14} \mathrm{O}_{8}$ & 929.6 & 929.6030 & 929.6043 & 1.4 & 11.4 & -1.66 \\
\hline 6 & $\mathrm{C}_{41} \mathrm{H}_{70} \mathrm{~N}_{10} \mathrm{O}_{8}$ & 831.5 & 831.5450 & 831.5451 & 0.1 & 9.3 & -2.43 \\
\hline 7 & $\mathrm{C}_{49} \mathrm{H}_{78} \mathrm{~N}_{14} \mathrm{O}_{8}$ & 991.6 & 991.6209 & 991.6200 & 0.9 & 12.5 & -1.26 \\
\hline 8 & $\mathrm{C}_{49} \mathrm{H}_{78} \mathrm{~N}_{14} \mathrm{O}_{8}$ & 991.5 & 991.6209 & 991.6200 & 0.9 & 12.5 & -1.26 \\
\hline 9 & $\mathrm{C}_{46} \mathrm{H}_{76} \mathrm{~N}_{14} \mathrm{O}_{8} \mathrm{~S}$ & 985.6 & 985.5804 & 985.5764 & 4 & 12.4 & -1.34 \\
\hline 10 & $\mathrm{C}_{49} \mathrm{H}_{78} \mathrm{~N}_{14} \mathrm{O}_{8}$ & 991.5 & 991.6209 & 991.6200 & 0.9 & 12.5 & -1.26 \\
\hline 11 & $\mathrm{C}_{46} \mathrm{H}_{76} \mathrm{~N}_{14} \mathrm{O}_{8} \mathrm{~S}$ & 985.6 & 985.5804 & 985.5764 & 4 & 12.4 & -1.34 \\
\hline 12 & $\mathrm{C}_{48} \mathrm{H}_{82} \mathrm{~N}_{14} \mathrm{O}_{8} \mathrm{~S}$ & 983.7 & 983.6525 & 983.6513 & 1.2 & 11.8 & -1.38 \\
\hline 13 & $\mathrm{C}_{44} \mathrm{H}_{76} \mathrm{~N}_{14} \mathrm{O}_{8}$ & 929.6 & 929.6041 & 929.6043 & 0.3 & 10.5 & -1.62 \\
\hline 14 & $\mathrm{C}_{44} \mathrm{H}_{76} \mathrm{~N}_{14} \mathrm{O}_{8}$ & 929.7 & 929.6040 & 929.6043 & -0.3 & 10.1 & -1.62 \\
\hline 15 & $\mathrm{C}_{44} \mathrm{H}_{76} \mathrm{~N}_{14} \mathrm{O}_{8}$ & 929.5 & 929.6023 & 929.6043 & 2.2 & 10.5 & -1.62 \\
\hline 16 & $\mathrm{C}_{44} \mathrm{H}_{76} \mathrm{~N}_{14} \mathrm{O}_{8}$ & $465.3^{\mathrm{e}}$ & $465.3055^{\mathrm{e}}$ & $465.3058^{e}$ & 0.3 & 10.0 & -1.62 \\
\hline 17 & $\mathrm{C}_{44} \mathrm{H}_{76} \mathrm{~N}_{14} \mathrm{O}_{8}$ & 929.6 & 929.6057 & 929.6043 & -1.5 & 9.9 & -1.62 \\
\hline 18 & $\mathrm{C}_{44} \mathrm{H}_{76} \mathrm{~N}_{14} \mathrm{O}_{8}$ & 929.7 & 929.6040 & 929.6043 & 0.4 & 12.1 & -1.62 \\
\hline 19 & $\mathrm{C}_{44} \mathrm{H}_{76} \mathrm{~N}_{14} \mathrm{O}_{8}$ & 929.6 & 929.6034 & 929.6043 & -1.0 & 12.4 & -1.62 \\
\hline 20 & $\mathrm{C}_{45} \mathrm{H}_{78} \mathrm{~N}_{14} \mathrm{O}_{8}$ & 943.6 & 943.6168 & 943.6200 & 3.4 & 11.7 & -1.62 \\
\hline 21 & $\mathrm{C}_{45} \mathrm{H}_{78} \mathrm{~N}_{14} \mathrm{O}_{8}$ & 943.7 & 943.6200 & 943.6200 & 0.0 & 9.7 & -1.62 \\
\hline
\end{tabular}

${ }^{a}(\mathrm{M}+\mathrm{H})^{+}$, ESI (Finnigan, Thermoelectron, LCQ classic). ${ }^{b}(\mathrm{M}+\mathrm{H})^{+}$, FAB-MS (JEOL HX110 sector instrument), or MALDI-TOF (Bruker Ultraflex III). ${ }^{c}$ Hewlett Packard 1100 (C-18, Microsorb-MV $\left.\mathrm{MV}^{\mathrm{TM}}, 4.6 \mathrm{~mm} \times 250 \mathrm{~mm}, 5 \mu \mathrm{m}\right)$ using a gradient system $(10-90 \%$ acetonitrile containing $0.1 \%$ TFA within 40 mins, $1 \mathrm{~mL} / \mathrm{min})$. Peptides $\geq 95 \%$ purity. ${ }^{d}$ http://www.vcclab.org/lab/alogps. ${ }^{e}(\mathrm{M}+2 \mathrm{H})^{2+}$ 